\title{
Identification and Characterization of Plant-Interacting Targets of Tomato Spotted Wilt Virus Silencing Suppressor
}

\author{
Ying Zhai, Prabu Gnanasekaran (D) and Hanu R. Pappu * \\ Department of Plant Pathology, Washington State University, Pullman, WA 99164, USA; \\ ying.zhai@wsu.edu (Y.Z.); prabu.gnanasekaran@wsu.edu (P.G.) \\ * Correspondence: hrp@wsu.edu
}

Citation: Zhai, Y.; Gnanasekaran, P.; Pappu, H.R. Identification and Characterization of Plant-Interacting Targets of Tomato Spotted Wilt Virus Silencing Suppressor. Pathogens 2021, 10, 27. https://doi.org/10.3390/ pathogens 10010027

Received: 29 September 2020 Accepted: 16 November 2020 Published: 1 January 2021

Publisher's Note: MDPI stays neutral with regard to jurisdictional claims in published maps and institutional affiliations.

Copyright: (c) 2021 by the authors. Licensee MDPI, Basel, Switzerland. This article is an open access article distributed under the terms and conditions of the Creative Commons Attribution (CC BY) license (https: / / creativecommons.org/ licenses/by/4.0/).

\begin{abstract}
Tomato spotted wilt virus (TSWV; species Tomato spotted wilt orthotospovirus) is an economically important plant virus that infects multiple horticultural crops on a global scale. TSWV encodes a non-structural protein NSs that acts as a suppressor of host RNA silencing machinery during infection. Despite extensive structural and functional analyses having been carried out on TSWV NSs, its protein-interacting targets in host plants are still largely unknown. Here, we systemically investigated NSs-interacting proteins in Nicotiana benthamiana via affinity purification and mass spectrometry (AP-MS) analysis. Forty-three TSWV NSs-interacting candidates were identified in N. benthamiana. Gene Ontology (GO) and protein-protein interaction (PPI) network analyses were carried out on their closest homologs in tobacco (Nicotiana tabacum), tomatoes (Solanum lycopersicum) and Arabidopsis (Arabidopsis thaliana). The results showed that NSs preferentially interacts with plant defense-related proteins such as calmodulin (CaM), importin, carbonic anhydrase and two heat shock proteins (HSPs): HSP70 and HSP90. As two major nodes in the PPI network, CaM and importin subunit $\alpha$ were selected for the further verification of their interactions with NSs via yeast two-hybrid $(\mathrm{Y} 2 \mathrm{H})$ screening. Our work suggests that the downstream signaling, transportation and/or metabolic pathways of host-NSs-interacting proteins may play critical roles in NSs-facilitated TSWV infection.
\end{abstract}

Keywords: affinity purification; calmodulin; carbonic anhydrase; heat shock protein; importin; mass spectrometry; NSs; protein-protein interaction network; RNA silencing suppressor; tomato spotted wilt virus

\section{Introduction}

Tomato spotted wilt virus (TSWV; species Tomato spotted wilt orthotospovirus) is the best known member in Orthotospovirus, which is the only genus with plant-infecting viruses in the family Tospoviridae [1]. Belonging to the order Bunyavirales, tospoviruses contain segmented RNA genomes with three single-stranded (ss) RNAs packaged in enveloped virus particles [2]. The large (L) RNA is negative sense, while the medium (M) and the small (S) RNAs possess an ambisense genome organization [3]. As a well-studied and economically important plant virus [4], TSWV causes significant yield losses in a wide range of agronomic and horticultural crops such as beans, lettuce, peanuts (groundnuts), peppers, potatoes, tobacco and tomatoes $[5,6]$.

The TSWV L RNA encodes an RNA-dependent RNA polymerase (RdRp). The M RNA encodes a non-structural movement protein NSm, and the precursor of two structural glycoproteins $\mathrm{G}_{\mathrm{N}}$ and $\mathrm{G}_{\mathrm{C}}$. A nucleocapsid protein $(\mathrm{N})$ and another non-structural protein (NSs) are encoded by the S RNA [7]. Both the M and S RNAs are organized in an ambisense manner [8]. The three genomic RNAs of TSWV and the $\mathrm{N}$ protein form ribonucleoproteins encapsulated by the glycoprotein $\left(G_{N}\right.$ and $\left.G_{C}\right)$ envelope. TSWV infects plants via the thrips vector in the field [9].

NSs proteins are widely found in plant- and vertebrate-infecting Bunyaviruses [10]. NSs proteins from different tospoviruses share a common feature of binding both small and long double-stranded (ds) RNAs [11]. As a non-structural protein, TSWV NSs acts as 
an RNA silencing suppressor for overcoming the host immunity barrier [12]. NSs is an avirulence determinant of the TSWV resistance gene Ts $w$ in peppers [13,14]. Tsw-mediated resistance in peppers can be overcome by a single amino acid change in NSs at position 104 (T-A) [15]. The N-terminal domain in NSs is important for its avirulence and RNA silencing suppression functions [16]. Two conserved motifs, GKV/T at positions 181-183 and $Y L$ at positions 412-413, are critical for the silencing suppressor function of NSs [7].

Despite the advancement of structural and functional research on TSWV NSs, its protein-interacting targets in host plants are still largely unknown. In this research, we investigated the NSs-interacting proteins in Nicotiana benthamiana via affinity purification and mass spectrometry (AP-MS) analysis. Gene Ontology (GO) and protein-protein interaction (PPI) network analyses were carried out on their closest homologs in Arabidopsis (Arabidopsis thaliana), tobacco (Nicotiana tabacum) and tomatoes (Solanum lycopersicum). Network analysis was carried out, followed by experimental validation by using the yeast two-hybrid $(\mathrm{Y} 2 \mathrm{H})$ assay. This approach of using AP-MS and network analysis combined with experimental validation offers an efficient approach for understanding the PPIs underlying virus-host interactions.

\section{Results}

2.1. Affinity Purification-Mass Spectrometry Analysis Reveals NSs-Interacting Proteins in N. benthamiana

TSWV NSs was fused with an mGFP5 tag at its C-terminal (NSs-GFP) and was transiently expressed in $N$. benthamiana leaves at the four-leaf stage. Its binding proteins were extracted and analyzed by AP-MS. To identify the host proteins that specifically interact with TSWV NSs, overlapping candidates were selected from two independent AP-MS replicates. The list was then compared to the list of candidates that bind the V2 protein of Croton yellow vein mosaic virus (unpublished), to remove overlapping non-specific interactors. Eventually, $43 \mathrm{~N}$. benthamiana proteins were found to specifically interact with TSWV NSs (Table 1). The list is arranged according to the numbers of peptide spectrum matches (\#PSMs), posterior error probability (PEP) values of the PSMs (Sum PEP Score) and sums of the scores of the individual peptides from the Sequest HT search (Score SEQUEST HT) in Replicate 1 (R1).

Multiple signaling-relevant proteins can be found in the NSs-interacting list, including a lectin receptor kinase (LecRK; A0A0K1U1X9), a mitogen-activated protein kinase (MAPK; A0A0C5LA06), a calcium-dependent protein kinase (CDPK; A0A1V1H6S6), a calmodulin (CaM) (U3MW48) and two serine/threonine protein kinases (STPKs; A0A4Y5QRT8 and Q5D1L7). Two heat shock proteins (HSPs), HSP70 (Q769C6) and HSP90 (A0A0M3SBS3), also interact with NSs. For these N. benthamiana interactors, their closest homologs in tobacco, tomatoes and Arabidopsis were found by BLASTP and are listed in Table 2. Both A0A286RNF7 and A4D0J9 are carbonic anhydrases with LOC107768773, Solyc02g086820 and AT3G01500 being their closest homologs in tobacco, tomatoes and Arabidopsis, respectively. Therefore, only 42 inferred homologous proteins in each species are listed (Table 2). 
Table 1. N. benthamiana protein-interacting candidates for tomato spotted wilt virus (TSWV) NSs revealed by affinity purification and mass spectrometry (AP-MS). Two independent replicates (designated as R1 and R2) were performed. The list is arranged according to the values of the numbers of peptide spectrum matches (\#PSMs), posterior error probability (PEP) values of the PSMs (Sum PEP Scores), and sums of the scores of the individual peptides from the Sequest HT search (Scores SEQUEST HT) in Replicate 1 (R1). Two bold candidates (importin subunit $\alpha$ and Calmodulin 3) were further confirmed to interact with NSs via yeast two-hybrid assays.

\begin{tabular}{|c|c|c|c|c|c|c|c|}
\hline \multirow[t]{2}{*}{ Accession } & \multirow[t]{2}{*}{ Description } & \multicolumn{2}{|c|}{ \#PSMs } & \multicolumn{2}{|c|}{ Sum PEP Scores } & \multicolumn{2}{|c|}{ Scores SEQUEST HT } \\
\hline & & R1 & $\mathrm{R} 2$ & $\mathrm{R} 1$ & $\mathrm{R} 2$ & R1 & $\mathrm{R} 2$ \\
\hline A0A286RNF7 & Carbonic anhydrase & 33 & 28 & 65.105 & 67.837 & 86.19 & 71.41 \\
\hline A0A0M3SBS3 & Heat shock protein $90-3$ & 28 & 26 & 50.052 & 58.461 & 63.66 & 48.87 \\
\hline A4D0J9 & Carbonic anhydrase (fragment) & 19 & 22 & 49.892 & 67.834 & 53.63 & 68.49 \\
\hline I3QHX5 & Adenosylhomocysteinase & 15 & 9 & 23.165 & 17.085 & 27.23 & 11.48 \\
\hline I0B7J2 & $\begin{array}{c}\text { Chloroplast photosystem II subunit } \mathrm{O} 2 \\
\text { (PSBO2) }\end{array}$ & 12 & 13 & 25.788 & 36.984 & 35.48 & 25.76 \\
\hline I0B7J5 & Chloroplast photosystem II subunit P1 (PSBP1) & 10 & 9 & 29.376 & 31.322 & 28.37 & 29.27 \\
\hline U5PY93 & MP-Interacting Protein (MIP) 1.2 & 10 & 6 & 18.593 & 13.573 & 23.1 & 12.96 \\
\hline Q769C6 & Heat shock protein 70 (fragment) & 9 & 4 & 9.018 & 7.495 & 18.44 & 6.57 \\
\hline U3MY90 & Proteinase inhibitor (fragment) & 8 & 10 & 19.765 & 31.157 & 20.94 & 26 \\
\hline A0A0A7EAV4 & Ankyrin repeat containing protein 2 (AKR2) & 6 & 2 & 10.561 & 4.414 & 12.68 & 2.11 \\
\hline F2Z9R2 & Glucose-6-phosphate 1-dehydrogenase (G6PD) & 6 & 2 & 7.83 & 2.791 & 10.65 & 1.79 \\
\hline A1YUL9 & Importin subunit $\alpha$ & 5 & 5 & 13.326 & 9.718 & 17.15 & 6.01 \\
\hline A0A0C4Y3N1 & RabG3c protein & 5 & 6 & 7.097 & 6.486 & 8.22 & 2.17 \\
\hline A0A0S3ANR1 & NB-LRR HR-associated cell death (NRC) 2a & 5 & 3 & 6.318 & 2.992 & 1.87 & 1.63 \\
\hline Q5YLB4 & DNA gyrase subunit B & 4 & 1 & 4.471 & 0.71 & 2.38 & 0 \\
\hline U3MW48 & Calmodulin 3 (fragment) & 3 & 1 & 8.901 & 2.829 & 10.37 & 2.46 \\
\hline Q5XPZ0 & Adenosine kinase (fragment) & 3 & 3 & 5.692 & 5.426 & 7.01 & 4.12 \\
\hline R4S2V6 & Lipoxygenase (fragment) & 3 & 1 & 3.467 & 0.731 & 2.21 & 0 \\
\hline A0A387K491 & Ran binding protein RanBP1-1b & 3 & 1 & 2.618 & 1.051 & 1.96 & 0 \\
\hline A0A0K1U1X9 & Clade XV lectin receptor kinase & 3 & 8 & 1.266 & 1.145 & 4.89 & 7.08 \\
\hline F8WQS4 & Quinone reductase (fragment) & 2 & 1 & 4.126 & 0.807 & 4.73 & 0 \\
\hline A0A172WC56 & Defensin-like protein 1 & 2 & 1 & 3.97 & 0.732 & 2.84 & 0 \\
\hline A2PYH3 & Nascent polypeptide associated complex $\alpha$ & 2 & 3 & 3.392 & 4.614 & 2.27 & 4.41 \\
\hline Q6XX16 & Glutathione S-transferase U2 (fragment) & 2 & 3 & 2.565 & 1.677 & 3.44 & 0 \\
\hline D6QX33 & Plastid RNA-binding protein & 2 & 1 & 2.326 & 0.695 & 0 & 0 \\
\hline A0A0C5LA06 & Mitogen-activated protein kinase & 2 & 2 & 2.143 & 1.889 & 1.65 & 0 \\
\hline F8WQS2 & Acetylglutamate kinase (fragment) & 1 & 2 & 3.648 & 2.075 & 3.27 & 0 \\
\hline A0A0A7HDA5 & Epi-aristolochene dihydroxylase & 1 & 2 & 3.296 & 2.77 & 3.53 & 1.72 \\
\hline Q18NX4 & Nitrate reductase & 1 & 1 & 2.896 & 1.947 & 2.65 & 0 \\
\hline B0CN62 & Myosin VIII-1 & 1 & 1 & 2.364 & 1.331 & 2.55 & 0 \\
\hline W6JJ90 & Nuclear pore complex protein Sec13d & 1 & 1 & 1.971 & 0.754 & 2.69 & 0 \\
\hline Q20KN2 & Metacaspase type II (fragment) & 1 & 1 & 1.969 & 2.13 & 0 & 1.72 \\
\hline Q5D1L7 & Serine/threonine protein kinase (fragment) & 1 & 1 & 1.888 & 1.185 & 2.11 & 0 \\
\hline Q2QFR2 & Cysteine proteinase glycinain type (fragment) & 1 & 1 & 1.627 & 1.227 & 2.28 & 0 \\
\hline$\widehat{\mathrm{C}} 9 \overline{\mathrm{DFC}} 0$ & Phytophthora-inhibited protease 1 (fragment) & 1 & 1 & 1.605 & 0.698 & 1.97 & 1.78 \\
\hline A0A4Y5QRT8 & Serine/threonine protein kinase PBS1a & 1 & 2 & 1.396 & 1.303 & 0 & 1.77 \\
\hline Q2QFR3 & Cysteine proteinase aleurain type & 1 & 1 & 1.191 & 1.367 & 0 & 1.62 \\
\hline A0A024B875 & $\begin{array}{c}\text { Dihydrolipoamide acetyltransferase } \\
\text { component }\end{array}$ & 1 & 1 & 1.003 & 1.596 & 2.28 & 0 \\
\hline D5JXY5 & Calcium-transporting ATPase & 1 & 1 & 0.754 & 0.754 & 0 & 0 \\
\hline A0A1V1H6S6 & Calcium-dependent protein kinase isoform 2 & 1 & 1 & 0.732 & 0.801 & 2.11 & 0 \\
\hline Q52JJ5 & Glutamyl-tRNA synthetase & 1 & 1 & 0.7 & 0.789 & 0 & 0 \\
\hline A7L4B4 & Histone H3 & 1 & 2 & 0.509 & 1.589 & 1.76 & 2.54 \\
\hline V5KY72 & Ubiquitin-conjugating enzyme variant & 1 & 1 & 0.503 & 0.766 & 0 & 0 \\
\hline
\end{tabular}


Table 2. The closest homologs of TSWV NSs-interacting candidates in tobacco (Nicotiana tabacum), tomatoes (Solanum lycopersicum) and Arabidopsis (Arabidopsis thaliana). Five bold candidates (HSP70, importin subunit $\alpha$, CaM, MAPK and $\mathrm{STPK}$ ) are major nodes in the protein-protein interaction (PPI) network.

\begin{tabular}{|c|c|c|c|}
\hline \multirow{2}{*}{ Description } & \multicolumn{3}{|c|}{ Closest Homologs in } \\
\hline & Tobacco & Tomato & Arabidopsis \\
\hline Carbonic anhydrase & LOC107768773 & Solyc02g086820 & AT3G01500 \\
\hline Heat shock protein 90 (HSP90) & LOC107768797 & Solyc12g015880 & AT5G56000 \\
\hline Adenosylhomocysteinase & LOC107783029 & Solyc09g092380 & AT4G13940 \\
\hline Chloroplast photosystem II subunit O2 (PSBO2) & LOC107766588 & Solyc02g065400 & AT3G50820 \\
\hline Chloroplast photosystem II subunit P1 (PSBP1) & LOC107830202 & Solyc07g044860 & AT1G06680 \\
\hline MP-interacting protein (MIP) 1.2 & LOC107801992 & Solyc04g009770 & AT3G44110 \\
\hline Heat shock protein 70 (HSP70) & LOC107803414 & Solyc11g066060 & AT3G12580 \\
\hline Proteinase inhibitor & LOC107799889 & Solyc03g019690 & AT1G17860 \\
\hline Ankyrin repeat containing protein 2 (AKR2) & LOC107793888 & Solyc01g104170 & AT2G17390 \\
\hline Glucose-6-phosphate 1-dehydrogenase (G6PD) & LOC107794892 & Solyc07g045540 & AT5G35790 \\
\hline Importin subunit $\alpha$ & LOC107810574 & Solyc01g060470 & AT4G16143 \\
\hline RabG3 protein & LOC107815360 & Solyc03g120750 & AT1G52280 \\
\hline NB-LRR HR-associated cell death (NRC) 2 & LOC107792680 & Solyc10g047320 & AT1G53350 \\
\hline DNA gyrase subunit B & LOC107786139 & Solyc12g021230 & AT5G04130 \\
\hline Calmodulin (CaM) & LOC107761764 & Solyc10g081170 & AT3G43810 \\
\hline Adenosine kinase & LOC107790330 & Solyc09g007940 & AT5G03300 \\
\hline Lipoxygenase & LOC107830099 & Solyc01g099160 & AT1G55020 \\
\hline Ran binding protein RanBP & LOC107771336 & Solyc08g062660 & AT5G58590 \\
\hline Lectin receptor kinase & LOC107782584 & Solyc03g080060 & AT5G55830 \\
\hline Quinone reductase (fragment) & LOC107761412 & Solyc10g006650 & AT4G27270 \\
\hline Defensin-like protein 1 & LOC107831752 & Solyc07g006380 & AT1G61070 \\
\hline Nascent polypeptide associated complex $\alpha$ & LOC107791866 & Solyc10g081030 & AT3G12390 \\
\hline Glutathione S-transferase U2 & LOC107782951 & Solyc07g056490 & AT1G78380 \\
\hline Plastid RNA-binding protein & LOC107787150 & Solyc03g111050 & AT3G48500 \\
\hline Mitogen-activated protein kinase (MAPK) & LOC107794128 & Solyc01g094960 & AT4G01370 \\
\hline Acetylglutamate kinase & LOC107803486 & Solyc11g005620 & AT3G57560 \\
\hline Epi-aristolochene dihydroxylase; CYP71B35 & LOC107759261 & Solyc04g083140 & AT3G26310 \\
\hline Nitrate reductase & LOC107785409 & Solyc11g013810 & AT1G37130 \\
\hline Myosin & LOC107806983 & Solyc02g020910 & AT3G19960 \\
\hline Nuclear pore complex protein SEC13 & LOC107777830 & Solyc02g087300 & AT2G30050 \\
\hline Metacaspase type II & LOC107824366 & Solyc09g098150 & AT1G79330 \\
\hline Serine/threonine protein kinase (STPK) & LOC107808522 & Solyc02g067030 & AT3G01090 \\
\hline Cysteine proteinase glycinain type & LOC107760226 & Solyc04g080960 & AT4G39090 \\
\hline PIP1; cysteine endopeptidase & LOC107774651 & Solyc02g077040 & AT3G48340 \\
\hline Serine/threonine protein kinase PBS1 & LOC107830934 & Solyc05g024290 & AT5G13160 \\
\hline Cysteine proteinase aleurain type & LOC107784768 & Solyc07g041900 & AT5G60360 \\
\hline Lipoamide acetyltransferase component & LOC107820956 & Solyc01g066520 & AT3G06850 \\
\hline Calcium-transporting ATPase & LOC107814306 & Solyc04g016260 & AT3G57330 \\
\hline Calcium-dependent protein kinase & LOC107805386 & Solyc07g064610 & AT3G20410 \\
\hline Glutamyl-tRNA synthetase & LOC107774917 & Solyc01g112290 & AT5G64050 \\
\hline Histone $\mathrm{H} 3$ & LOC107759185 & Solyc01g073970 & AT5G65360 \\
\hline Ubiquitin-conjugating enzyme variant & LOC107831808 & Solyc04g007960 & AT1G70660 \\
\hline
\end{tabular}

\subsection{Gene Ontology Overrepresentation/Enrichment Tests of NSs-Interacting Proteins}

To facilitate GO analysis, the closest tobacco, tomato and Arabidopsis homologs inferred from the $N$. benthamiana NSs-interacting proteins (Table 2) were used for overrepresentation/enrichment tests. Only the Arabidopsis homologs generated meaningful results in the GO biological process test that classified proteins according to the cellular activities in which they were involved (Table 3). Defense-responsive proteins were found to be enriched by about 10 fold (Table 3), which is consistent with the virulent nature of NSs. The defense-related proteins in the list include a LecRK (AT5G55830), a carbonic anhydrase (AT3G01500), chloroplast photosystem II subunit P1 (PSBP1; AT1G06680), a CaM (AT3G43810), 
a lipoxygenase (AT1G55020), STPK PBS1 (AT5G13160), a MAPK (AT4G01370), a cysteine proteinase (AT4G39090), a defensin-like protein (AT1G61070), a calcium-transporting ATPase (AT3G57330) and a NB-LRR protein required for hypersensitive response (HR)-associated cell death (NRC) (AT1G53350). The host immunity responses triggered by these defense proteins may be suppressed by the binding of NSs during TSWV infection.

Meaningful results were obtained when using tomato and Arabidopsis homologs in the GO cellular component overrepresentation test (Table 4). In tomato homologs, lysosomal enzymes localized in the extracellular space were enriched by about 40 to 50 fold (Table 5), which include three cysteine proteases: Solyc07g041900, Solyc02g077040 and Solyc04g080960. Similarly, in Arabidopsis homologs, lysosome- and chloroplast-localized proteins were found to be enriched by more than 40 and 7 fold, respectively (Table 5). The three lysosome-localized Arabidopsis homologs include an aleurain-type cysteine proteinase (AT5G60360), a KDEL-tailed cysteine endopeptidase (AT3G48340) and a glycinain-type cysteine proteinase (AT4G39090). Actually, all four Arabidopsis cysteine proteinases characterized in the GO molecular function test are localized in the lysosome, except the type-II metacaspase (AT1G79330). The chloroplast-localized Arabidopsis proteins in the list include a carbonic anhydrase (AT3G01500), PSBP1 (AT1G06680), a glutamate-tRNA ligase (AT5G64050), chloroplast photosystem II subunit O2 (PSBO2; AT3G50820), a glutathione S-transferase (GST; AT1G78380), HSP90 (AT5G56000), a plastid RNA-binding protein (AT3G48500) and glucose-6-phosphate 1-dehydrogenase (G6PD1; AT5G35790).

Table 3. PANTHER overrepresentation test of Gene Ontology (GO) biological processes using Arabidopsis homologs inferred from NSs-interacting proteins. A total of 27,416 proteins (GO Ontology database, doi:10.5281/zenodo.3980761) were included in the Arabidopsis reference list. Fisher's exact test with Bonferroni correction for multiple testing was adopted. Only results with Bonferroni-corrected $p<0.05$ are displayed.

\begin{tabular}{|c|c|c|c|c|c|c|}
\hline \multirow{2}{*}{ GO Biological Process Complete } & \multirow{2}{*}{$\begin{array}{l}\text { Arabidopsis } \\
\text { Reference \# }\end{array}$} & \multicolumn{5}{|c|}{ NSs-Interacting Proteins } \\
\hline & & $\#$ & Expected & $\begin{array}{l}\text { Fold } \\
\text { Enrichment }\end{array}$ & $+1-$ & $p$ Value \\
\hline Defense response to bacterium & 413 & 7 & 0.63 & 11.06 & + & $9.04 \times 10^{-3}$ \\
\hline Response to bacterium & 506 & 8 & 0.78 & 10.32 & + & $2.75 \times 10^{-3}$ \\
\hline Response to other organisms & 1092 & 12 & 1.67 & 7.17 & + & $1.74 \times 10^{-4}$ \\
\hline $\begin{array}{l}\text { Interspecies interaction between } \\
\text { organisms }\end{array}$ & 1120 & 12 & 1.72 & 6.99 & + & $2.28 \times 10^{-4}$ \\
\hline Response to external biotic stimulus & 1092 & 12 & 1.67 & 7.17 & + & $1.74 \times 10^{-4}$ \\
\hline Response to biotic stimulus & 1093 & 12 & 1.67 & 7.17 & + & $1.75 \times 10^{-4}$ \\
\hline Response to stimulus & 5567 & 22 & 8.53 & 2.58 & + & $1.20 \times 10^{-2}$ \\
\hline Response to external stimulus & 1509 & 15 & 2.31 & 6.49 & + & $9.27 \times 10^{-6}$ \\
\hline Defense response to other organisms & 805 & 9 & 1.23 & 7.30 & + & $8.95 \times 10^{-3}$ \\
\hline Defense response & 952 & 10 & 1.46 & 6.86 & + & $4.03 \times 10^{-3}$ \\
\hline Response to stress & 3091 & 18 & 4.74 & 3.80 & + & $6.09 \times 10^{-4}$ \\
\hline Cellular process & 11,979 & 33 & 18.35 & 1.80 & + & $1.67 \times 10^{-2}$ \\
\hline Unclassified & 5450 & 5 & 8.35 & 0.60 & - & 0.00 \\
\hline
\end{tabular}

Arabidopsis reference \#: number of proteins that are classified in the category out of 27,416 Arabidopsis reference proteins. NSs-interacting protein candidate \#: number of NSs-interacting proteins that are classified in the category out of 42 candidates; Expected: expected number of NSs-interacting proteins that are classified in the category out of 42 candidates; Fold enrichment: fold enrichment of NSs-interacting proteins that are classified in the category, calculated as \#/Expected; +/-: significantly enriched/diluted. 
Table 4. PANTHER overrepresentation test of GO molecular function using tobacco and Arabidopsis homologs inferred from N. benthamiana NSs-interacting proteins. A total of 61,238 proteins (GO Ontology database, doi:10.5281/zenodo.4033054) were included in the tobacco reference list. All other test parameters are the same as those in Table 3.

\begin{tabular}{|c|c|c|c|c|c|c|}
\hline \multirow{2}{*}{ GO Molecular Function Complete } & \multirow{2}{*}{$\begin{array}{c}\text { Tobacco } \\
\text { Reference \# }\end{array}$} & \multicolumn{5}{|c|}{ NSs-Interacting Proteins } \\
\hline & & $\#$ & Expected & $\begin{array}{c}\text { Fold } \\
\text { Enrichment }\end{array}$ & $+1-$ & $p$ Value \\
\hline Unfolded protein binding & 284 & 4 & 0.16 & 24.64 & + & $4.15 \times 10^{-2}$ \\
\hline Binding & 21,517 & 26 & 12.30 & 2.11 & + & $5.53 \times 10^{-3}$ \\
\hline ATP binding & 4591 & 12 & 2.62 & 4.57 & + & $9.61 \times 10^{-3}$ \\
\hline Adenyl ribonucleotide binding & 4708 & 12 & 2.69 & 4.46 & + & $1.24 \times 10^{-2}$ \\
\hline Adenyl nucleotide binding & 4734 & 12 & 2.71 & 4.44 & + & $1.32 \times 10^{-2}$ \\
\hline Purine nucleotide binding & 5258 & 13 & 3.01 & 4.33 & + & $6.22 \times 10^{-3}$ \\
\hline Nucleotide binding & 5870 & 16 & 3.35 & 4.77 & + & $6.52 \times 10^{-5}$ \\
\hline Small molecule binding & 6512 & 17 & 3.72 & 4.57 & + & $3.66 \times 10^{-5}$ \\
\hline Nucleoside phosphate binding & 5870 & 16 & 3.35 & 4.77 & + & $6.52 \times 10^{-5}$ \\
\hline Purine ribonucleotide binding & 5217 & 13 & 2.98 & 4.36 & + & $5.70 \times 10^{-3}$ \\
\hline Ribonucleotide binding & 5285 & 14 & 3.02 & 4.63 & + & $9.62 \times 10^{-4}$ \\
\hline Carbohydrate derivative binding & 5332 & 14 & 3.05 & 4.59 & + & $1.07 \times 10^{-3}$ \\
\hline Purine ribonucleoside triphosphate binding & 5100 & 13 & 2.91 & 4.46 & + & $4.43 \times 10^{-3}$ \\
\hline Anion binding & 6438 & 16 & 3.68 & 4.35 & + & $2.38 \times 10^{-4}$ \\
\hline Ion binding & 11,853 & 20 & 6.77 & 2.95 & + & $1.59 \times 10^{-3}$ \\
\hline Unclassified & 26,668 & 2 & 15.24 & 0.13 & - & 0.00 \\
\hline Cysteine-type endopeptidase activity & 72 & 4 & 0.11 & 36.26 & + & $9.91 \times 10^{-3}$ \\
\hline Cysteine-type peptidase activity & 102 & 4 & 0.16 & 25.60 & + & $3.71 \times 10^{-2}$ \\
\hline Catalytic activity & 8305 & 27 & 12.72 & 2.12 & + & $1.06 \times 10^{-2}$ \\
\hline Cation binding & 1647 & 11 & 2.52 & 4.36 & + & $5.00 \times 10^{-2}$ \\
\hline Ion binding & 3071 & 16 & 4.70 & 3.40 & + & $1.04 \times 10^{-2}$ \\
\hline Binding & 9721 & 31 & 14.89 & 2.08 & + & $1.26 \times 10^{-3}$ \\
\hline Protein binding & 5109 & 23 & 7.83 & 2.94 & + & $3.25 \times 10^{-4}$ \\
\hline Unclassified & 5502 & 1 & 8.43 & 0.12 & - & 0.00 \\
\hline
\end{tabular}

Tobacco reference \#: number of proteins that are classified in the category out of 61,238 Nicotiana tabacum reference proteins. All other column descriptions are the same as those in Table 3.

\subsection{The Protein-Protein Interaction Network of NSs-Interacting Proteins}

To explore the indirect and expanded consequences of physical interactions between NSs and plant proteins, a PPI network was constructed for 42 Arabidopsis homologs inferred from N. benthamiana NSs-interacting proteins (Figure 1A and Figure S1; Table S1). A total of 1346 interactions were predicted. Five major node proteins can be found in the PPI network, including HSP70 (At3G12580), CaM (AT3G43810), MAPK (AT4G01370), STPK (AT3G01090) and importin subunit $\alpha$ (AT4G16143) (Figure 1A). Interactions between NSs and these five plant signaling, chaperone and transporter proteins may play significant roles in TSWV infection. We further investigated interactions within the 42 Arabidopsis homologs (Figure 1B). The most reliable interaction was predicted to occur between HSP70 and HSP90 (Figure 1B). Ten proteins including HSP70 and HSP90 were predicted to have self-interactions (Figure 1B). As two major nodes in the PPI network, CaM and importin subunit $\alpha$ were selected for the further verification of their interactions with TSWV NSs. 
Table 5. PANTHER overrepresentation test of GO cellular components using tomato and Arabidopsis homologs inferred from N. benthamiana NSs-interacting proteins. A total of 34,637 proteins (GO Ontology database, doi:10.5281/zenodo.4033054) were included in the tomato reference list. All other parameters are the same as those in Table 3.

\begin{tabular}{|c|c|c|c|c|c|c|}
\hline \multirow{2}{*}{ GO Cellular Component Complete } & \multirow{2}{*}{$\begin{array}{c}\text { Tomato } \\
\text { Reference \# }\end{array}$} & \multicolumn{5}{|c|}{ NSs-Interacting Proteins } \\
\hline & & $\#$ & Expected & $\begin{array}{l}\text { Fold } \\
\text { Enrichment }\end{array}$ & $+1-$ & $p$ Value \\
\hline Lysosome & 49 & 3 & 0.06 & 50.49 & + & $1.71 \times 10^{-2}$ \\
\hline Lytic vacuole & 52 & 3 & 0.06 & 47.58 & + & $2.02 \times 10^{-2}$ \\
\hline $\begin{array}{l}\text { Intracellular membrane-bounded } \\
\text { organelle }\end{array}$ & 5532 & 18 & 6.71 & 2.68 & + & $1.61 \times 10^{-2}$ \\
\hline Membrane-bounded organelle & 5782 & 19 & 7.01 & 2.71 & + & $7.25 \times 10^{-3}$ \\
\hline Organelle & 6262 & 19 & 7.59 & 2.50 & + & $2.30 \times 10^{-2}$ \\
\hline Cellular anatomical entity & 9174 & 26 & 11.12 & 2.34 & + & $7.57 \times 10^{-4}$ \\
\hline Intracellular organelle & 6130 & 19 & 7.43 & 2.56 & + & $1.70 \times 10^{-2}$ \\
\hline Intracellular & 7723 & 25 & 9.36 & 2.67 & + & $1.09 \times 10^{-4}$ \\
\hline Cytoplasm & 5053 & 21 & 6.13 & 3.43 & + & $3.26 \times 10^{-5}$ \\
\hline Extracellular space & 62 & 3 & 0.08 & 39.90 & + & $3.34 \times 10^{-2}$ \\
\hline Unclassified & 25,226 & 16 & 30.59 & 0.52 & - & 0.00 \\
\hline \multirow{2}{*}{ GO Cellular Component Complete } & \multirow{2}{*}{$\begin{array}{l}\text { Arabidopsis } \\
\text { Reference \# }\end{array}$} & \multicolumn{5}{|c|}{ NSs-Interacting Proteins } \\
\hline & & $\#$ & Expected & $\begin{array}{c}\text { Fold } \\
\text { Enrichment }\end{array}$ & $+1-$ & $p$ Value \\
\hline Lysosome & 46 & 3 & 0.07 & 42.57 & + & $3.98 \times 10^{-2}$ \\
\hline Vacuole & 1084 & 10 & 1.66 & 6.02 & + & $3.03 \times 10^{-3}$ \\
\hline Cytoplasm & 14,776 & 38 & 22.64 & 1.68 & + & $3.25 \times 10^{-4}$ \\
\hline Chloroplast stroma & 718 & 8 & 1.10 & 7.27 & + & $8.34 \times 10^{-3}$ \\
\hline Plastid stroma & 730 & 8 & 1.12 & 7.15 & + & $9.39 \times 10^{-3}$ \\
\hline Whole membrane & 830 & 8 & 1.27 & 6.29 & + & $2.33 \times 10^{-2}$ \\
\hline Membrane & 5495 & 22 & 8.42 & 2.61 & + & $2.28 \times 10^{-3}$ \\
\hline Bounding membrane of organelle & 921 & 8 & 1.41 & 5.67 & + & $4.82 \times 10^{-2}$ \\
\hline Cytosol & 3242 & 22 & 4.97 & 4.43 & + & $1.35 \times 10^{-7}$ \\
\hline Plasma membrane & 3529 & 18 & 5.41 & 3.33 & + & $1.05 \times 10^{-3}$ \\
\hline Cell periphery & 4001 & 19 & 6.13 & 3.10 & + & $1.35 \times 10^{-3}$ \\
\hline Unclassified & 1877 & 1 & 2.88 & 0.35 & - & 0.00 \\
\hline
\end{tabular}

Tomato reference \#: number of proteins that are classified in the category out of 34,637 Solanum lycopersicum reference proteins. All other column descriptions are the same as those in Table 3. 
A

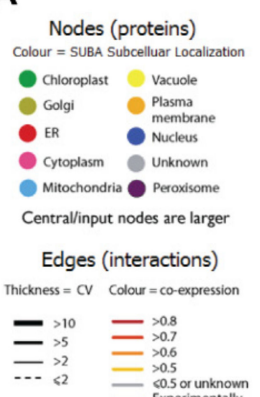

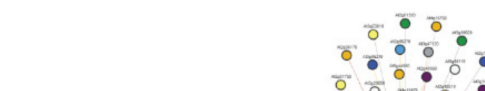

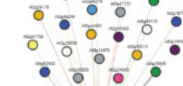

Adenosylhomocysteinase.

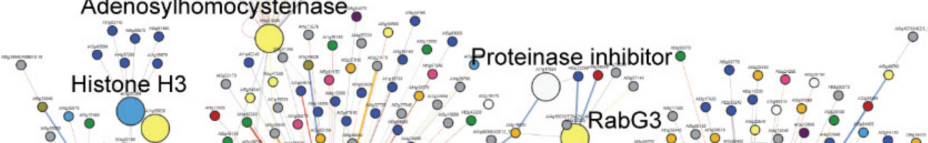

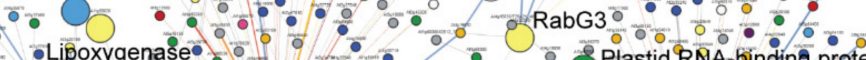

AKR2 Lipoxygenase

Thickness $=C V \quad$ colour $=c 0$

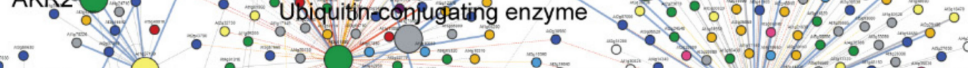

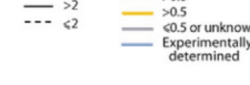

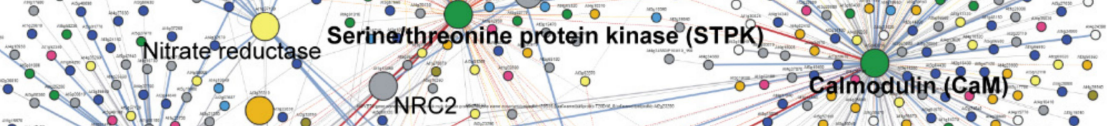

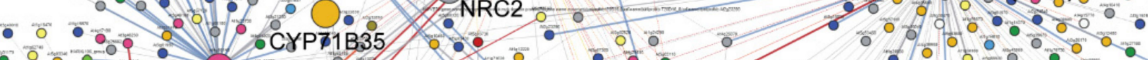

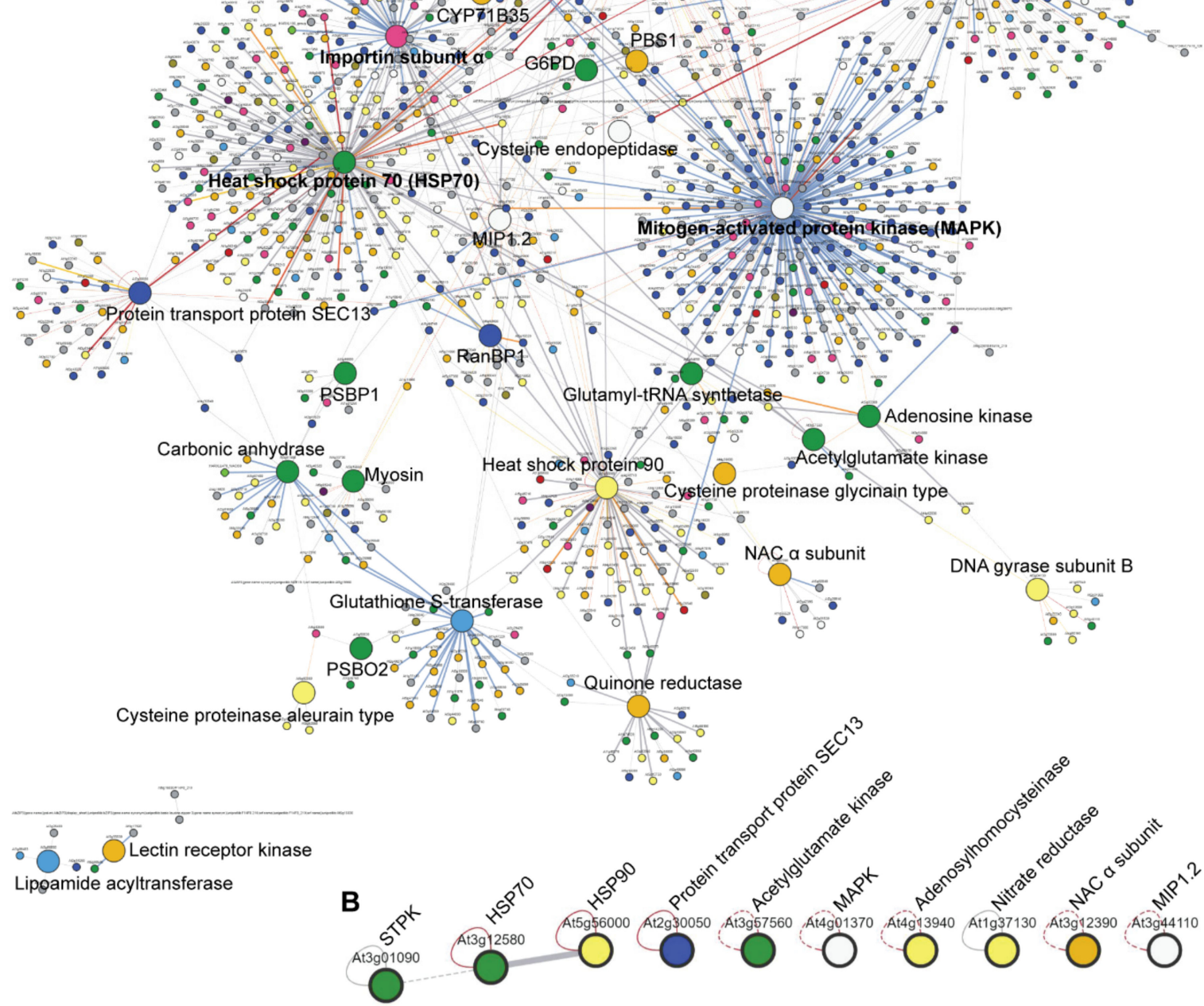

Figure 1. (A) The protein-protein interaction (PPI) network of 42 Arabidopsis homologs inferred from N. benthamiana NSs-interacting proteins. A total of 1346 interactions were predicted. HSP70, CaM, MAPK, STPK and importin subunit $\alpha$ are five major nodes found in the PPI network. (B) Predicted interactions within the 42 Arabidopsis homologs. The most reliable interaction occurs between HSP70 and HSP90. Ten proteins including HSP70 and HSP90 have self-interactions.

\subsection{Importin Subunit $\alpha$ and Calmodulin 3 Interact with NSs in Targeted Yeast Two-Hybrid Assays}

$N$. benthamiana importin subunit $\alpha$ (A1YUL9) and CaM 3 (U3MW48) were selected to verify their interactions with NSs via targeted $\mathrm{Y} 2 \mathrm{H}$. Both proteins interacted with NSs in the assays (Figure 2), which demonstrates that the AP-MS approach is effective and reliable in identifying host-NSs-interacting proteins. 

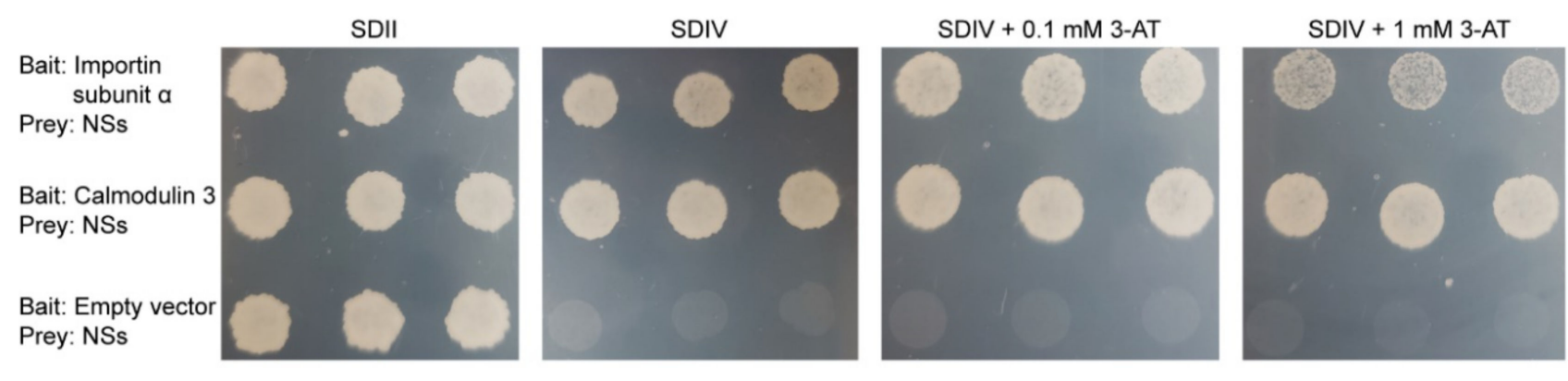

Figure 2. N. benthamiana proteins importin subunit $\alpha$ and Calmodulin 3 (CaM 3) were verified to interact with tomato spotted wilt virus NSs via targeted yeast two-hybrid (Y2H). Positive interactions were implied by the yeast's ability to grow on synthetic defined (SD) selection medium minus four elements of uracil, histidine, leucine and tryptophan (SDIV) and its tolerance to the His3p enzyme inhibitor 3-aminotriazole (3-AT). All yeast clones grow normally on the SDII medium which only lacks leucine and tryptophan. Two concentrations of 3-AT ( 0.1 and $1 \mathrm{mM})$ were used in the test.

\section{Discussion}

Although NSs is well-known for its RNA silencing suppressor function during the TSWV infection process, the direct protein-interacting targets of NSs in plant hosts are still largely unknown. There is a report that TSWV NSs can suppress jasmonate signaling in plants [17] via direct interactions with three basic-helix-loop-helix (bHLH) transcription factors (TFs): MYC2, MYC3 and MYC4 [18]. In this work, we significantly expanded the reservoir of NSs' physical interactors in plants. The interactions may be critical for TSWV virulence.

Multiple NSs-interacting proteins identified in this research have been demonstrated to regulate plant defenses. For example, cysteine proteinases play prominent roles in plant-pathogen interactions [19]. Notably, tomato aleurain-type cysteine proteinase can be inhibited by the pathogenic oomycete Phytophthora [20]. NSs-interacting cysteine proteinases are critical for lysosome-mediated autophagy function, which acts as an antiviral defense mechanism in plants. Viruses counteract host defenses by hijacking the autophagy pathway [21]. Interactions between NSs and lysosome-localized cysteine proteinases may contribute to the TSWV-induced suppression of autophagy.

N. benthamiana CaM 3 and importin subunit $\alpha$ are two NSs interactors verified by both AP-MS and $\mathrm{Y} 2 \mathrm{H}$ assays. CaMs are significant components in plant immunity signaling networks [22]. There are multiple lines of evidence showing that CaMs participate in plant defenses against bacterial [23], fungal [24] and viral [25-28] pathogens. A tobacco CaM can bind the RNA silencing suppressor encoded by Cucumber mosaic virus and thereby trigger its degradation via the autophagy pathway [25]. On the contrary, an N. benthamiana CaM is required for the RNA silencing suppressor function of $\beta C 1$, which is encoded by the geminivirus Tomato yellow leaf curl China virus [26]. Thus, the interaction between $N$. benthamiana CaM 3 and TSWV NSs may lead to either NSs degradation or the activation of its RNA silencing suppressor activity. Further investigations would reveal whether CaM 3 plays a positive or negative role in the NSs-mediated suppression of plant RNA silencing.

Importins are critical for the nuclear import of Agrobacterium virulence proteins [29]. There are multiple reports demonstrating that plant importin subunit $\alpha$ facilitates the nuclear transportation of viral proteins. N. plumbaginifolia importin subunit $\alpha$ can bind the coat/capsid proteins (CPs) of Rice tungro bacilliform virus and Mungbean yellow mosaic virus and transport them into the nucleus [30]. Similarly, tobacco importin subunit $\alpha$ mediates the nuclear import of Cauliflower mosaic virus translational transactivator protein P6, which suppresses plant RNA silencing in the nucleus [31]. N. benthamiana importin subunit $\alpha$ has a similar function of transporting viral proteins. For example, it interacts with the $\mathrm{CP}$ of Beet black scorch virus and transports it into the nucleus [32]. The nuclear localization of the Potato mop-top virus Triple Gene Block1 (TGB1) protein is mediated by N. benthamiana importin subunit $\alpha$, which facilitates systemic virus movement [33]. The Pelargonium line 
pattern virus $\mathrm{p} 37$ protein acts as an RNA silencing suppressor whose nuclear localization is also mediated by $N$. benthamiana importin subunit $\alpha$ [34]. Taken together, we postulate that the physical interaction between TSWV NSs and importin subunit $\alpha$ may facilitate the nuclear transportation of NSs and the following exertion of its RNA silencing suppressor activity.

Since many plant virus infection events occur in the chloroplast [35] and are regulated by host photosynthetic and photomorphogenic activities [36], it is not surprising that NSs interacts with multiple chloroplast-localized proteins. Chloroplast-localized carbonic anhydrases appeared twice in our refined N. benthamiana NSs interactor list (Table 1). Their antioxidant activity is involved in plant HR defenses [37]. For example, carbonic anhydrase expression is indispensable for potato resistance to the late blight pathogen Phytophthora infestans [38]. It is possible that NSs interacts with plant carbonic anhydrases to suppress their antioxidant function, thereby promoting TSWV infection.

Both HSP70 and HSP90 were found to interact with TSWV NSs in our AP-MS analysis (Table 1). HSP70 is a major node in the PPI network of NSs-interacting proteins (Figure 1A). Functional and physical interactions between HSP70 and HSP90 exist ubiquitously in bacteria, yeasts [39] and plants [40]. In Arabidopsis, HSP70 expression can be induced by infections by multiple virus species [41]. In tomatoes, the Tomato yellow leaf curl virus CP interacts with HSP70 to facilitate virus infection [42]. In N. benthamiana, HSP90 is indispensable for plant resistance against Potato virus X and Tobacco mosaic virus [43]. Based on these reports, HSP70 and HSP90 may interact with NSs to positively or negatively regulate TSWV infection.

Overall, the NSs-interacting proteins identified via AP-MS provide multiple clues for dissecting the roles of NSs in TSWV-host interaction. CaM-triggered defense signaling, importin-facilitated protein nuclear transportation, carbonic anhydrase-catalyzed antioxidation and HSP70/HSP90-mediated stress tolerance emerged as principal plant cellular activities in response to NSs invasion. In the future, the molecular mechanisms of how TSWV NSs interacts with these defense-related proteins (e.g., time and spatial patterns); the genetic, biochemical and physiological outcomes of the interactions; the expression changes of downstream genes triggered by the interactions; and the regulatory/regulated proteins up-/downstream of the interaction cascades should be investigated to obtain more details. The obtained results would provide a comprehensive portrait of NSs' activities in the plant cell.

\section{Materials and Methods}

\subsection{Plasmids and Gene Cloning}

The TSWV NSs coding sequence (CDS) was previously described [8]. The NSs CDS was amplified using the PCR primers $5^{\prime}$-GGGGACAAGTTTGTACAAAAAAGCAGGCTAT GTCTTCAAGTGTTTATGAG-3' and $5^{\prime}$-GGGGACCACTTTGTACAAGAAAGCTGGGTGT TTTGATCCTGAAGCATA-3'. The amplified NSs CDS was cloned into the Gateway Donor vector pDONR 207 (Invitrogen) via a BP reaction (insertion of the att-B-sequence-containing PCR product into the att $\mathrm{P}$ recombination sites) and then inserted into the destination expression vector pEarleyGate 103 [44] from pDONR 207 via an LR reaction (insertion of the att-L-sequence-containing DNA into the att $\mathrm{R}$ recombination sites). In pEarleyGate 103, NSs was fused with an mGFP5 tag at its C-terminal (NSs-GFP). All the PCR-amplified sequences used in this research were verified by sequencing.

\subsection{Affinity Purification-Mass Spectrometry Analysis of NSs-Interacting Proteins}

NSs-GFP was transiently expressed in N. benthamiana leaves by agroinfiltration. Leaf samples were collected two days after infiltration, and the expression of NSs-GFP was verified by Western blotting. AP-MS was carried out using the GFP-Trap beads (Chromotek, Germany) as previously described $[45,46]$. Briefly, infiltrated leaves were ground into fine powder in liquid nitrogen, mixed with protein extraction buffer ( $1 \mathrm{~mL}$ per $500 \mathrm{mg}$ of tissue) and then thawed on ice. After incubation and centrifugation at $4{ }^{\circ} \mathrm{C}$, the extract supernatant was cleaned by filtration and then mixed with the GFP-Trap beads. After $1 \mathrm{~h}$ of incubation 
at $4{ }^{\circ} \mathrm{C}$, the mixture was subsequently washed with wash buffer $3-5$ times. The mass spectrometry (MS) analysis of the immunoprecipitated proteins was performed at the BGI Americas MS Service Center. The MS data were searched against the most updated Uniprot N. benthamiana database (2020_05) [47] using SEQUEST HT 2013 [48].

\subsection{Refinement of the NSs-Interacting Protein Candidate List}

Two NSs-GFP AP-MS biological replicates as well as two non-NSs AP-MS control replicates were performed for NSs-GFP. Since the Gateway-compatible pEarleyGate 103 cannot express mGFP5 without gene insertion, a pEarleyGate 103 construct expressing an mGFP5-fused V2 protein from Croton yellow vein mosaic virus was used as the non-NSs AP-MS control. Overlapping NSs-interacting protein candidates were identified from the two NSs-GFP AP-MS replicates. Non-specific NSs interactors were then removed from the list, including mGFP5, ubiquitin and proteins that were found to also interact with V2 in the control samples. This step helped to exclude non-specific NSs-interacting proteins that are expressed at high levels in N. benthamiana.

\subsection{Verification of NSs-Interacting Proteins by Targeted Yeast Two-Hybrid Assay}

Two N. benthamiana proteins in the interacting list, importin subunit $\alpha$ (A1YUL9) and CaM 3 (U3MW48), were selected to verify their interactions with NSs via targeted $\mathrm{Y} 2 \mathrm{H}$. The $\mathrm{Y} 2 \mathrm{H}$ procedure has been described previously [49]. In brief, the NSs CDS was cloned into the Gateway-compatible prey vector pACT2-GW (pACT2-GW-NSs, with leucine selection marker) and then used to transform yeast strain A. After testing the transformed yeast clones for self-activation, the importin subunit $\alpha$ or CaM 3 CDS was cloned into the Gatewaycompatible bait vector pBTM116-D9 with tryptophan selection marker and then used to transform a selected yeast line harboring pACT2-GW-NSs. Empty pBTM116-D9 was used as a negative control. Positive interactions were implied by the observation of the yeast's growth on synthetic defined (SD) selection medium minus four elements of uracil, histidine, leucine and tryptophan (SDIV) and its tolerance to the His3p enzyme inhibitor 3-aminotriazole (3-AT).

\subsection{Gene Ontology Analysis of Inferred Tobacco, Tomato and Arabidopsis Homologs}

Since there is currently no available ontology data and analysis tool for N. benthamiana, the GO analysis of NSs-interacting proteins was performed using their closest homologs in tobacco, tomatoes and Arabidopsis. Tobacco is a close relative of N. benthamiana, and the genome of tomatoes has been well-studied compared to other species in the Solanaceae family. However, neither tobacco nor tomatoes have annotation information sufficient for a comprehensive GO analysis. Thus, Arabidopsis homologs were still used for all the GO enrichment tests for biological processes, molecular functions and cellular components. The test results for tobacco and tomato homologs were included if they contained meaningful information. All the tests were performed using the PANTHER (Version 15.0) GO Term Enrichment tools [50].

\subsection{Protein-Protein Interaction Network Analysis of Inferred Arabidopsis Homologs}

Arabidopsis homologs were used for the protein-protein interaction (PPI) network analysis due to the availability of PPI data and analysis tools. The PPI analysis of the Arabidopsis homologs inferred from the $N$. benthamiana NSs-interacting proteins was performed using the Bio-Analytic Resource (BAR) Arabidopsis Interactions Viewer [51]. The queries included interaction data and predictions from BioGrid (Version 4.1) [52], IntAct (Version 4.2.16) [53] and BAR (Version 20-04) [51]. The results of protein-DNA interactions from the BAR were also included. 


\subsection{Mass Spectrometry Data Deposit}

The original AP-MS dataset (RAW files) and results of NSs-interacting candidates in $N$. benthamiana were deposited in the ProteomeXchange Consortium via the PRoteomics IDEntifications (PRIDE) [54] partner repository, with the dataset identifier PXD022401.

Supplementary Materials: The following are available online at https://www.mdpi.com/2076 -0817/10/1/27/s1. Figure S1: Protein-protein interaction (PPI) map of 42 Arabidopsis homologs inferred from $N$. benthamiana NSs-interacting proteins (the original map of Figure 2A). Table S1: Protein-protein interaction (PPI) network of 42 Arabidopsis homologs inferred from N. benthamiana NSs-interacting proteins.

Author Contributions: Conceptualization: Y.Z. and H.R.P.; data curation: Y.Z.; formal analysis: Y.Z.; funding acquisition: H.R.P.; investigation: Y.Z.; methodology: Y.Z.; project administration: Y.Z. and H.R.P.; supervision: H.R.P.; validation: Y.Z. and H.R.P.; writing—original draft: Y.Z.; writing—review and editing: Y.Z., P.G. and H.R.P. All authors have read and agreed to the published version of the manuscript.

Funding: This research and the APC were funded by the USDA National Institute of Food and Agriculture, Hatch project, Accession \#1016563, "Reducing the Impact of Pests and Diseases Affecting Washington Agriculture" (award to H.R.P.), and the Carl F. and James J. Chuey Endowment for Dahlia Research through the Scheetz Chuey Foundation (to H.R.P.).

Conflicts of Interest: The authors declare no conflict of interest.

\section{References}

1. Siddell, S.G.; Walker, P.J.; Lefkowitz, E.J.; Mushegian, A.R.; Adams, M.J.; Dutilh, B.E.; Gorbalenya, A.E.; Harrach, B.; Harrison, R.L.; Junglen, S.; et al. Additional changes to taxonomy ratified in a special vote by the International Committee on Taxonomy of Viruses (October 2018). Arch. Virol. 2019, 164, 943-946. [CrossRef]

2. Zhu, M.; van Grinsven, I.L.; Kormelink, R.; Tao, X. Paving the way to tospovirus infection: Multilined interplays with plant innate immunity. Annu. Rev. Phytopathol. 2019, 57, 41-62. [CrossRef] [PubMed]

3. Adkins, S. Tomato spotted wilt virus-Positive steps towards negative success. Mol. Plant Pathol. 2000, 1, 151-157. [CrossRef] [PubMed]

4. Scholthof, K.B.; Adkins, S.; Czosnek, H.; Palukaitis, P.; Jacquot, E.; Hohn, T.; Hohn, B.; Saunders, K.; Candresse, T.; Ahlquist, P.; et al. Top 10 plant viruses in molecular plant pathology. Mol. Plant Pathol. 2011, 12, 938-954. [CrossRef] [PubMed]

5. Pappu, H.R.; Jones, R.A.; Jain, R.K. Global status of tospovirus epidemics in diverse cropping systems: Successes achieved and challenges ahead. Virus Res. 2009, 141, 219-236. [CrossRef]

6. Oliver, J.E.; Whitfield, A.E. The genus Tospovirus: Emerging Bunyaviruses that threaten food security. Annu. Rev. Virol. 2016, 3, 101-124. [CrossRef]

7. Zhai, Y.; Bag, S.; Mitter, N.; Turina, M.; Pappu, H.R. Mutational analysis of two highly conserved motifs in the silencing suppressor encoded by Tomato spotted wilt virus (genus Tospovirus, family Bunyaviridae). Arch. Virol. 2014, 159, 1499-1504. [CrossRef]

8. Zhai, Y.; Peng, H.; Neff, M.M.; Pappu, H.R. Putative auxin and light responsive promoter elements from the Tomato spotted wilt tospovirus genome, when expressed as cDNA, are functional in Arabidopsis. Front. Plant Sci. 2019, 10, 804. [CrossRef]

9. Turina, M.; Kormelink, R.; Resende, R.O. Resistance to tospoviruses in vegetable crops: Epidemiological and molecular aspects. Annu. Rev. Phytopathol. 2016, 54, 347-371. [CrossRef]

10. Hedil, M.; Kormelink, R. Viral RNA silencing suppression: The enigma of Bunyavirus NSs proteins. Viruses 2016, 8, 208. [CrossRef]

11. Hedil, M.; de Ronde, D.; Kormelink, R. Biochemical analysis of NSs from different tospoviruses. Virus Res. 2017, 242, 149-155. [CrossRef] [PubMed]

12. Takeda, A.; Sugiyama, K.; Nagano, H.; Mori, M.; Kaido, M.; Mise, K.; Tsuda, S.; Okuno, T. Identification of a novel RNA silencing suppressor, NSs protein of Tomato spotted wilt virus. FEBS Lett. 2002, 532, 75-79. [CrossRef]

13. Margaria, P.; Ciuffo, M.; Pacifico, D.; Turina, M. Evidence that the nonstructural protein of Tomato spotted wilt virus is the avirulence determinant in the interaction with resistant pepper carrying the Tsw gene. Mol. Plant Microbe Interact. 2007, 20,547-558. [CrossRef] [PubMed]

14. De Ronde, D.; Butterbach, P.; Lohuis, D.; Hedil, M.; van Lent, J.W.; Kormelink, R. Tsw gene-based resistance is triggered by a functional RNA silencing suppressor protein of the Tomato spotted wilt virus. Mol. Plant Pathol. 2013, 14, 405-415. [CrossRef] [PubMed]

15. Almási, A.; Nemes, K.; Csömör, Z.; Tóbiás, I.; Palkovics, L.; Salánki, K. A single point mutation in Tomato spotted wilt virus NSs protein is sufficient to overcome Tsw-gene-mediated resistance in pepper. J. Gen. Virol. 2017, 98, 1521-1525. [CrossRef] [PubMed]

16. De Ronde, D.; Pasquier, A.; Ying, S.; Butterbach, P.; Lohuis, D.; Kormelink, R. Analysis of Tomato spotted wilt virus NSs protein indicates the importance of the N-terminal domain for avirulence and RNA silencing suppression. Mol. Plant Pathol. 2014, 15, 185-195. [CrossRef] 
17. Zhao, L.; Hu, Z.; Li, S.; Zhou, X.; Li, J.; Su, X.; Zhang, L.; Zhang, Z.; Dong, J. Diterpenoid compounds from Wedelia trilobata induce resistance to Tomato spotted wilt virus via the JA signal pathway in tobacco plants. Sci. Rep. 2019, 9, 2763. [CrossRef]

18. Wu, X.; Xu, S.; Zhao, P.; Zhang, X.; Yao, X.; Sun, Y.; Fang, R.; Ye, J. The Orthotospovirus nonstructural protein NSs suppresses plant MYC-regulated jasmonate signaling leading to enhanced vector attraction and performance. PLoS Pathog. 2019, 15, e1007897. [CrossRef]

19. Thomas, E.L.; van der Hoorn, R.A.L. Ten prominent host proteases in plant-pathogen interactions. Int. J. Mol. Sci. 2018, 19, 639. [CrossRef]

20. Tian, M.; Win, J.; Song, J.; van der Hoorn, R.; van der Knaap, E.; Kamoun, S. A Phytophthora infestans cystatin-like protein targets a novel tomato papain-like apoplastic protease. Plant Physiol. 2007, 143, 364-377. [CrossRef]

21. Yang, M.; Ismayil, A.; Liu, Y. Autophagy in plant-virus interactions. Annu. Rev. Virol. 2020, 7, 403-419. [CrossRef] [PubMed]

22. Cheval, C.; Aldon, D.; Galaud, J.P.; Ranty, B. Calcium/calmodulin-mediated regulation of plant immunity. Biochim. Biophys. Acta 2013, 1833, 1766-1771. [CrossRef]

23. Chiasson, D.; Ekengren, S.K.; Martin, G.B.; Dobney, S.L.; Snedden, W.A. Calmodulin-like proteins from Arabidopsis and tomato are involved in host defense against Pseudomonas syringae pv. Tomato. Plant Mol. Biol. 2005, 58, 887-897. [CrossRef] [PubMed]

24. Takabatake, R.; Karita, E.; Seo, S.; Mitsuhara, I.; Kuchitsu, K.; Ohashi, Y. Pathogen-induced calmodulin isoforms in basal resistance against bacterial and fungal pathogens in tobacco. Plant Cell Physiol. 2007, 48, 414-423. [CrossRef] [PubMed]

25. Nakahara, K.S.; Masuta, C.; Yamada, S.; Shimura, H.; Kashihara, Y.; Wada, T.S.; Meguro, A.; Goto, K.; Tadamura, K.; Sueda K.; et al. Tobacco calmodulin-like protein provides secondary defense by binding to and directing degradation of virus RNA silencing suppressors. Proc. Natl. Acad. Sci. USA 2012, 109, 10113-10118. [CrossRef] [PubMed]

26. Li, F.; Huang, C.; Li, Z.; Zhou, X. Suppression of RNA silencing by a plant DNA virus satellite requires a host calmodulin-like protein to repress RDR6 expression. PLoS Pathog. 2014, 10, e1003921. [CrossRef]

27. Bhattacharjee, S.; Lee, L.Y.; Oltmanns, H.; Cao, H.; Veena; Cuperus, J.; Gelvin, S.B. IMPa-4, an Arabidopsis importin $\alpha$ isoform, is preferentially involved in Agrobacterium-mediated plant transformation. Plant Cell 2008, 20, 2661-2680. [CrossRef]

28. Chung, Y.H.; Lacatus, G.; Sunter, G. Geminivirus AL2 protein induces expression of, and interacts with, a calmodulin-like gene, an endogenous regulator of gene silencing. Virology 2014, 460-461, 108-118. [CrossRef]

29. Li, F.; Zhao, N.; Li, Z.; Xu, X.; Wang, Y.; Yang, X.; Liu, S.S.; Wang, A.; Zhou, X. A calmodulin-like protein suppresses RNA silencing and promotes geminivirus infection by degrading SGS3 via the autophagy pathway in Nicotiana benthamiana. PLoS Pathog. 2017, 13, e1006213. [CrossRef]

30. Guerra-Peraza, O.; Kirk, D.; Seltzer, V.; Veluthambi, K.; Schmit, A.C.; Hohn, T.; Herzog, E. Coat proteins of Rice tungro bacilliform virus and Mungbean yellow mosaic virus contain multiple nuclear-localization signals and interact with importin alpha. J. Gen. Virol. 2005, 86, 1815-1826. [CrossRef]

31. Haas, G.; Azevedo, J.; Moissiard, G.; Geldreich, A.; Himber, C.; Bureau, M.; Fukuhara, T.; Keller, M.; Voinnet, O. Nuclear import of CaMV P6 is required for infection and suppression of the RNA silencing factor DRB4. EMBO J. 2008, 27, 2102-2112. [CrossRef] [PubMed]

32. Zhang, Y.; Zhang, X.; Niu, S.; Han, C.; Yu, J.; Li, D. Nuclear localization of Beet black scorch virus capsid protein and its interaction with importin $\alpha$. Virus Res. 2011, 155, 307-315. [CrossRef] [PubMed]

33. Lukhovitskaya, N.I.; Cowan, G.H.; Vetukuri, R.R.; Tilsner, J.; Torrance, L.; Savenkov, E.I. Importin- $\alpha$-mediated nucleolar localization of Potato mop-top virus TRIPLE GENE BLOCK1 (TGB1) protein facilitates virus systemic movement, whereas TGB1 self-interaction is required for cell-to-cell movement in Nicotiana benthamiana. Plant Physiol. 2015, 167, 738-752. [CrossRef] [PubMed]

34. Pérez-Cañamás, M.; Hernández, C. New insights into the nucleolar localization of a plant RNA virus-encoded protein that acts in both RNA packaging and RNA silencing suppression: Involvement of importins $\alpha$ and relevance for viral infection. Mol. Plant Microbe Interact. 2018, 31, 1134-1144. [CrossRef]

35. Bhattacharyya, D.; Chakraborty, S. Chloroplast: The Trojan horse in plant-virus interaction. Mol. Plant Pathol. 2018, 19, 504-518. [CrossRef]

36. Zhai, Y.; Peng, H.; Neff, M.M.; Pappu, H.R. Emerging molecular links between plant photomorphogenesis and virus resistance. Front. Plant Sci. 2020, 11, 920. [CrossRef]

37. Slaymaker, D.H.; Navarre, D.A.; Clark, D.; del Pozo, O.; Martin, G.B.; Klessig, D.F. The tobacco salicylic acid-binding protein 3 (SABP3) is the chloroplast carbonic anhydrase, which exhibits antioxidant activity and plays a role in the hypersensitive defense response. Proc. Natl. Acad. Sci. USA 2002, 99, 11640-11645. [CrossRef]

38. Restrepo, S.; Myers, K.L.; del Pozo, O.; Martin, G.B.; Hart, A.L.; Buell, C.R.; Fry, W.E.; Smart, C.D. Gene profiling of a compatible interaction between Phytophthora infestans and Solanum tuberosum suggests a role for carbonic anhydrase. Mol. Plant Microbe Interact. 2005, 18, 913-922. [CrossRef]

39. Kravats, A.N.; Hoskins, J.R.; Reidy, M.; Johnson, J.L.; Doyle, S.M.; Genest, O.; Masison, D.C.; Wickner, S. Functional and physical interaction between yeast Hsp90 and Hsp70. Proc. Natl. Acad. Sci. USA 2018, 115, E2210-E2219. [CrossRef]

40. Hahn, A.; Bublak, D.; Schleiff, E.; Scharf, K.D. Crosstalk between Hsp90 and Hsp70 chaperones and heat stress transcription factors in tomato. Plant Cell 2011, 23, 741-755. [CrossRef]

41. Aparicio, F.; Thomas, C.L.; Lederer, C.; Niu, Y.; Wang, D.; Maule, A.J. Virus induction of heat shock protein 70 reflects a general response to protein accumulation in the plant cytosol. Plant Physiol. 2005, 138, 529-536. [CrossRef] [PubMed] 
42. Gorovits, R.; Moshe, A.; Ghanim, M.; Czosnek, H. Recruitment of the host plant heat shock protein 70 by Tomato yellow leaf curl virus coat protein is required for virus infection. PLoS ONE 2013, 8, e70280. [CrossRef] [PubMed]

43. Lu, R.; Malcuit, I.; Moffett, P.; Ruiz, M.T.; Peart, J.; Wu, A.J.; Rathjen, J.P.; Bendahmane, A.; Day, L.; Baulcombe, D.C. High throughput virus-induced gene silencing implicates heat shock protein 90 in plant disease resistance. EMBO J. 2003, 22, 5690-5699. [CrossRef] [PubMed]

44. Earley, K.W.; Haag, J.R.; Pontes, O.; Opper, K.; Juehne, T.; Song, K.; Pikaard, C.S. Gateway-compatible vectors for plant functional genomics and proteomics. Plant J. 2006, 45, 616-629. [CrossRef]

45. Wang, L.; Ding, X.; Xiao, J.; Jiménez-Góngora, T.; Liu, R.; Lozano-Durán, R. Inference of a geminivirus-host protein-protein interaction network through affinity purification and mass spectrometry analysis. Viruses 2017, 9, 275. [CrossRef]

46. Sang, Y.; Wang, Y.; Ni, H.; Cazalé, A.C.; She, Y.M.; Peeters, N.; Macho, A.P. The Ralstonia solanacearum type III effector RipAY targets plant redox regulators to suppress immune responses. Mol. Plant Pathol. 2018, 19, 129-142. [CrossRef]

47. UniProt Consortium. UniProt: A worldwide hub of protein knowledge. Nucleic Acids Res. 2019, 47, D506-D515. [CrossRef]

48. Brodbelt, J.S.; Russell, D.H. Focus on the 20-year anniversary of SEQUEST. J. Am. Soc. Mass Spectrom. 2015, 26, 1797-1798. [CrossRef]

49. Peng, H.; Neff, M.M. Circadian Clock Associated 1 and ATAF2 differentially suppress cytochrome P450-mediated brassinosteroid inactivation. J. Exp. Bot. 2020, 71, 970-985. [CrossRef]

50. Mi, H.; Muruganujan, A.; Ebert, D.; Huang, X.; Thomas, P.D. PANTHER version 14: More genomes, a new PANTHER GO-slim and improvements in enrichment analysis tools. Nucleic Acids Res. 2019, 47, D419-D426. [CrossRef]

51. Geisler-Lee, J.; O’Toole, N.; Ammar, R.; Provart, N.J.; Millar, A.H.; Geisler, M. A predicted interactome for Arabidopsis. Plant Physiol. 2007, 145, 317-329. [CrossRef] [PubMed]

52. Oughtred, R.; Stark, C.; Breitkreutz, B.J.; Rust, J.; Boucher, L.; Chang, C.; Kolas, N.; O’Donnell, L.; Leung, G.; McAdam, R.; et al. The BioGRID interaction database: 2019 update. Nucleic Acids Res. 2019, 47, D529-D541. [CrossRef] [PubMed]

53. Kerrien, S.; Aranda, B.; Breuza, L.; Bridge, A.; Broackes-Carter, F.; Chen, C.; Duesbury, M.; Dumousseau, M.; Feuermann, M.; Hinz, U.; et al. The IntAct molecular interaction database in 2012. Nucleic Acids Res. 2012, 40, D841-D846. [CrossRef] [PubMed]

54. Perez-Riverol, Y.; Csordas, A.; Bai, J.; Bernal-Llinares, M.; Hewapathirana, S.; Kundu, D.J.; Inuganti, A.; Griss, J.; Mayer, G.; Eisenacher, M.; et al. The PRIDE database and related tools and resources in 2019: Improving support for quantification data. Nucleic Acids Res. 2019, 47, D442-D450. [CrossRef] [PubMed] 